\title{
Improving mechanical properties of multi- walled carbon nanotube/epoxy composites through a simple stretch-drawing method
}

- Tran Huu Nam

- Vu Minh Hung

- Pham Hong Quang

Petrovietnam University

(Manuscript Received on July 13th, 2016, Manuscript Revised December 06th, 2016)

\begin{abstract}
Horizontally aligned multi-walled carbon from straightening of the wavy CNTs and nanotube (CNT) sheets were produced from vertically aligned CNT arrays using drawing and winding techniques. Composites based on epoxy resin and an aligned 100-ply CNT sheet have been developed using hot-melt prepreg processing. However, wavy and poor-packed CNTs in the sheets have limited reinforcement efficiency of the CNTs in the composites. In this study, a new simple stretch-drawing method was used to modify the structures of the aligned CNT sheets for improving the composite properties. The stretch-drawing of the CNT sheets enhanced the composite properties considerably. The improved properties of the composites originated increasing the CNT dense packing in the composites. With a $3 \%$ stretch ratio, the aligned CNT/epoxy composites achieved their best mechanical properties in this study. The $3 \%$ stretched composites exhibit increased tensile strength by $113 \%$ and enhanced elastic modulus by $34 \%$ compared to non-stretched ones. Results show that the simple stretch-drawing is effective to produce highly aligned CNT sheets for the development of high-performance CNT composites. Compared to our previous stretching method, the stretch-drawing method in this study is more effective in improving the mechanical properties of aligned CNT/epoxy composites.
\end{abstract}

Key words: carbon nanotubes, prepregs, composites, stretching, mechanical properties.

\section{INTRODUCTION}

Carbon nanotubes (CNTs) have been regarded as the reinforcing agents for polymer composites because of their high aspect ratio, high surface area available for stress transfer, and excellent mechanical properties [1]. However, most CNT-reinforced polymer composites have been composed by unorganized CNTs dispersed in polymer matrices [2]. Those composites could not fully take advantage of the excellent properties of CNTs because of low volume fraction and easy agglomeration in the dispersion of CNTs. Therefore, recent studies have focused on developing vertically aligned CNT arrays [3] and horizontally aligned CNT sheets [4]. The aligned CNT sheets have been used to create aligned CNT/epoxy composites. Although the composites contain the aligned 
CNTs, their mechanical properties are low partly because of wavy and poor-packed CNTs in the composites [5]. Therefore, a mechanical stretching of the aligned CNT sheets has been applied to reduce wavy and poorly packed CNTs [6,7]. However, the handling of the CNT sheets without resin for the stretching is generally difficult because of static electricity [5]. To overcome this difficulty, a simple stretch-drawing method was proposed in this study to straighten the wavy CNTs and to reduce the poor-packed CNTs for improving their composite properties. Effect of the stretchdrawing on the mechanical properties of aligned CNT/epoxy composites was examined.

\section{EXPERIMENTAL PROCEDURES}

\subsection{Materials}

A B-stage epoxy resin film covered with release paper and plastic film was obtained from Sanyu Rec Co. Ltd. (Osaka, Japan) with the recommended cure condition of $130^{\circ} \mathrm{C}$ for $2 \mathrm{~h}$. The areal weight of the B-stage epoxy resin film with density of $1.2 \mathrm{~g} / \mathrm{cm}^{3}$ was controlled to approximately $12 \mathrm{~g} / \mathrm{m}^{2}$. Vertically aligned CNT arrays with about $0.8 \mathrm{~mm}$ height were grown on a bare quartz substrate using chloride-mediated chemical vapor deposition [3]. As-grown CNTs examined have mean diameter of $38 \mathrm{~nm}[6,7]$.

\subsection{Processing of aligned CNT sheets}

Pristine aligned and multiply CNT sheets were produced from the vertically aligned CNT arrays using drawing and winding processes. Detailed procedures were presented in several reports [4-7]. The stacked 100-ply aligned CNT sheets were used for composite fabrication.

\subsection{A simple stretch-drawing of CNT sheets}

The simple stretch-drawing was applied to the aligned CNT sheets with round tube shaped using a cylinder with different top and bottom diameters (Figure 1). The stretch ratio $\Delta$ was calculated using the following equation.

$$
\Delta=\frac{D-D_{O}}{D_{O}}
$$

Therein, $D_{O}$ and $D$ are the top and bottom diameters of the cylinder used for stretch-drawing the CNT sheets with round tube shaped, respectively. The top diameter $D_{O}$ is 50 $\mathrm{mm}$ and the bottom diameters are $51 \mathrm{~mm}$ and $51.5 \mathrm{~mm}$ corresponding to the respective stretch ratios of $2 \%$ and $3 \%$. Efforts to carry out $4 \%$ stretching corresponding to the bottom diameter of $52 \mathrm{~mm}$ were not successful because of sheet breakage. (a)

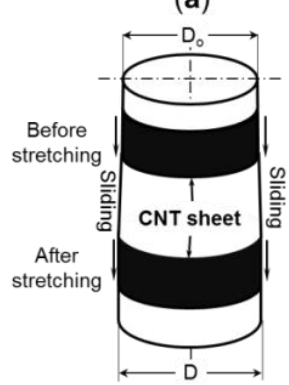

(b)

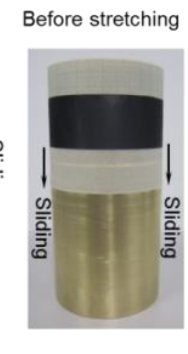

(c)

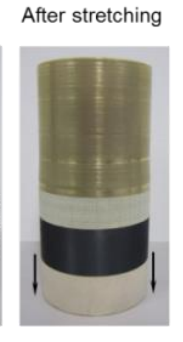

Figure 1. (a) A schematic diagram of the stretchdrawing processes. The images showing the processes

(b) before stretching and (c) after stretching.

\subsection{Fabrication of CNT/epoxy composites}

Composites made of an epoxy resin film and a 100-ply CNT sheet were developed using hot-melt prepreg processing with a vacuumassisted system (VAS). First, the CNT sheet with round tube shaped was spread into a flat sheet. Next, a flat CNT sheet with $20 \mathrm{~mm}$ width and $50 \mathrm{~mm}$ length was covered with an epoxy resin film and was set between two release films 
(WL5200; Airtech International Inc., CA, USA) to create an aligned CNT/epoxy prepreg. The prepreg was fabricated under $0.5 \mathrm{MPa}$ pressure for $5 \mathrm{~min}$ at $100{ }^{\circ} \mathrm{C}$ using a test press (MPWNL; Toyo Seiki Seisaku-sho Ltd., Tokyo, Japan). Finally, the prepreg was placed on the VAS and was cured at $130{ }^{\circ} \mathrm{C}$ for $2 \mathrm{~h}$ under 2 $\mathrm{MPa}$ in the test press to produce an aligned CNT/epoxy composite. The pristine and stretched CNT/epoxy composites were fabricated for comparative assessments.

\subsection{Thermogravimetric analysis}

The thermal degradation of epoxy resin, the CNTs, and their composites was analyzed up to $800^{\circ} \mathrm{C}$ in argon gas at a flow rate of $300 \mathrm{ml} / \mathrm{min}$ using a thermogravimetric analyzer (DTG-60A; Shimadzu Corp., Kyoto, Japan). About 5 mg of each specimen was loaded for each measurement at a heating rate of $10^{\circ} \mathrm{C} / \mathrm{min}$. The respective mass losses of epoxy resin, the CNTs, and the composites were recorded.

\subsection{Characterizations and testing}

Field emission scanning electron microscopy (FE-SEM) (SU8030; Hitachi Ltd., Tokyo, Japan) was used to investigate the microstructural morphologies of the CNT sheets and their composites. Polarized Raman spectra were measured to determine the degree of CNT alignment in the sheets and their composites using Raman spectroscope (XploRA-ONE; Horiba Ltd., Kyoto, Japan). Tensile testing was conducted for the composites in a laboratory environment. Tensile specimens with $10 \mathrm{~mm}$ gauge length were tested on a testing machine (EZ-L; Shimadzu Corp., Kyoto, Japan) with a crosshead speed of $0.1 \mathrm{~mm} / \mathrm{min}$. Widths of specimens were measured using an optical microscope (SZX12; Olympus Corp., Tokyo,
Japan), whereas their thickness was measured using a micrometer (102-119; Mitutoyo Corp., Kanagawa, Japan). The fracture strain was measured using a non-contacting extensometer (TRViewX; Shimadzu Corp., Kyoto, Japan) with two targets. Mean tensile properties were obtained from at least five specimens.

\section{RESULTS AND DISCUSSION}

\subsection{Evaluation of the simple stretch-drawing on alignment of CNTs in the sheets}

FE-SEM images showing microstructural morphologies of the pristine and stretched CNT sheets are presented in Figure 2. The pristine CNT sheets in Figure 2a showed many wavy and poor-packed CNTs. After the simple stretch-drawing (Figure 1), the wavy CNTs in the sheets decreased considerably (Figures 2b2c). Besides, the stretch-drawing enhances the dense packing of CNTs in the sheets. Moreover, the 3\% stretched CNT sheets showed more straight CNTs and greater CNT alignment than the $2 \%$ stretched CNT sheets (Figures 2b-2c).

The alignment and straightening of the wavy CNTs after stretch-drawing were examined using polarized Raman spectroscopy [7-9]. Polarized Raman spectra with Raman shift between 1000-2000 $\mathrm{cm}^{-1}$ were measured using incident laser light with a wavelength of $532 \mathrm{~nm}$ normal to the CNT sheet samples (Figure 3). The incident light was polarized parallel and perpendicular to the CNT alignment (see Figure 3 inset). Polarized Raman spectra for all samples show two main peaks located at approximately $1350 \mathrm{~cm}^{-1}$ and $1580 \mathrm{~cm}^{-1}$, which are attributed respectively to the disorderinduced $\mathrm{D}$ band and the graphite-structure derived $\mathrm{G}$ band. The Raman shift of the CNT sheets does not change significantly after stretch-drawing.

Moreover, the G-band intensity ratio $R$ in 
the parallel configuration to the perpendicular configuration was estimated to examine the degree of CNT alignment [7-9]. The higher CNT alignment produces the higher G-band intensity ratio because Raman scattering is more intense when the polarization of the incident light is parallel to the axis of a CNT [9]. The Gband intensity ratio $R$ of the pristine CNT sheets was 1.67 . After $2 \%$ stretching, the $R$ value of the
CNT sheets was enhanced to 2.44. Particularly, the $R$ value of the CNT sheets with $3 \%$ stretch ratio increased drastically to 3.03 . Results show that the G-band intensity ratio of the $3 \%$ stretched samples is greater than that of the $2 \%$ stretched ones. The enhancement in the $R$ is attributed to the better alignment of CNTs in the stretched sheets (Figure 2) caused by higher stretch ratio.
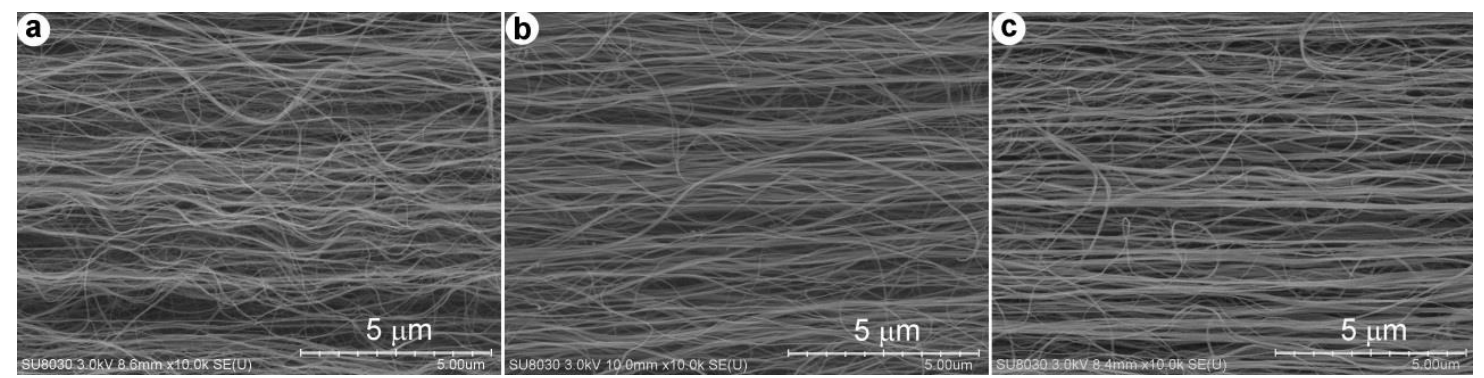

Figure 2. FE-SEM micrographs showing microstructural morphologies of (a) pristine, (b) $2 \%$ and (c) $3 \%$ stretched CNT sheets.

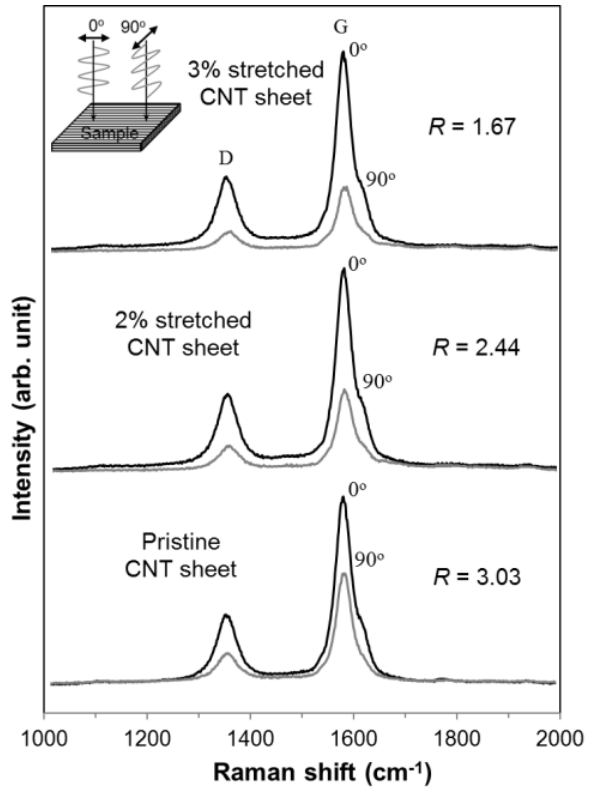

Figure 3. Polarized Raman spectra of pristine and stretched CNT sheets at $0^{\circ}$ and $90^{\circ}\left(0^{\circ}\right.$ and $90^{\circ}$ directions correspond to configurations where the polarization direction of the laser light are, respectively, parallel and perpendicular to the direction of CNTs).

\subsection{CNT volume fraction in the composites}

The CNT volume fraction was ascertained via the TGA data. The respective mass losses of the CNTs, epoxy resin and the composites were measured at $150-750^{\circ} \mathrm{C}$. The CNT mass fraction $\left(m_{f}\right)$ of the composite was calculated from the mass loss of the CNTs $\left(\Delta m_{f}\right)$, epoxy resin $\left(\Delta m_{m}\right)$ and the composite $\left(\Delta m_{c}\right)$ as below.

$$
m_{f}=\frac{\left(\Delta m_{m}-\Delta m_{c}\right)}{\left(\Delta m_{m}-\Delta m_{f}\right)}
$$

The CNT volume fraction $\left(V_{f}\right)$ was then estimated from the mass fraction of the CNTs, epoxy resin density $\left(\rho_{m}\right)$, and the density of the composite $\left(\rho_{c}\right)$ as follows.

$$
V_{f}=1-\frac{\left(1-m_{f}\right) \rho_{c}}{\rho_{m}}
$$

\section{Trang 38}


The mass losses, CNT mass fractions, and CNT volume fractions of the composites are presented in Table 1.

Table 1. Properties of epoxy resin, the CNTs and the composites

\begin{tabular}{|c|c|c|c|c|}
\hline Materials & $\begin{array}{c}\text { Thicknes } \\
\mathrm{s}(\mu \mathrm{m})\end{array}$ & $\begin{array}{c}\text { Mass } \\
\text { loss }(\%)\end{array}$ & $\begin{array}{c}\text { CNT m } \\
(\%)\end{array}$ & $\begin{array}{c}\text { CNT V } \\
(\text { vol. } \%)\end{array}$ \\
\hline Epoxy resin & $8-10$ & 87.9 & - & - \\
\hline CNTs & - & 2.59 & - & - \\
\hline $\begin{array}{c}\text { Pristine } \\
\text { composites }\end{array}$ & $16-19$ & 47.1 & 47.8 & 35.5 \\
\hline $\begin{array}{c}2 \% \text { stretched } \\
\text { composites }\end{array}$ & $14-16$ & 45.4 & 49.8 & 37.3 \\
\hline $\begin{array}{c}3 \% \text { stretched } \\
\text { composites }\end{array}$ & $14-16$ & 44.1 & 51.4 & 38.8 \\
\hline
\end{tabular}

The stretch-drawing of the sheets induced a slight enhancement of the CNT volume fraction in the composites. The increase of the CNT volume fraction was explained by the reduced composite thickness [6-7]. The reduced composite thickness is attributed to the straightening of wavy CNTs and increasing the dense packing of CNTs in the sheets. The 3\% stretching engendered more straightening of wavy CNTs and denser packing of CNTs compared to the $2 \%$ stretching.

\subsection{Effects of stretch-drawing on the mechanical properties of the composites}

Mechanical properties of the pristine and stretched CNT/epoxy composites are presented in Figure 4. Mean tensile strength, elastic modulus, and fracture strain of epoxy resin respectively were $64.4 \mathrm{MPa}, 2.6 \mathrm{GPa}$, and $4.8 \%$ [7]. FE-SEM micrographs showing in-plane distribution of CNTs in the pristine and stretched CNT/epoxy composites are depicted in Figure 5.
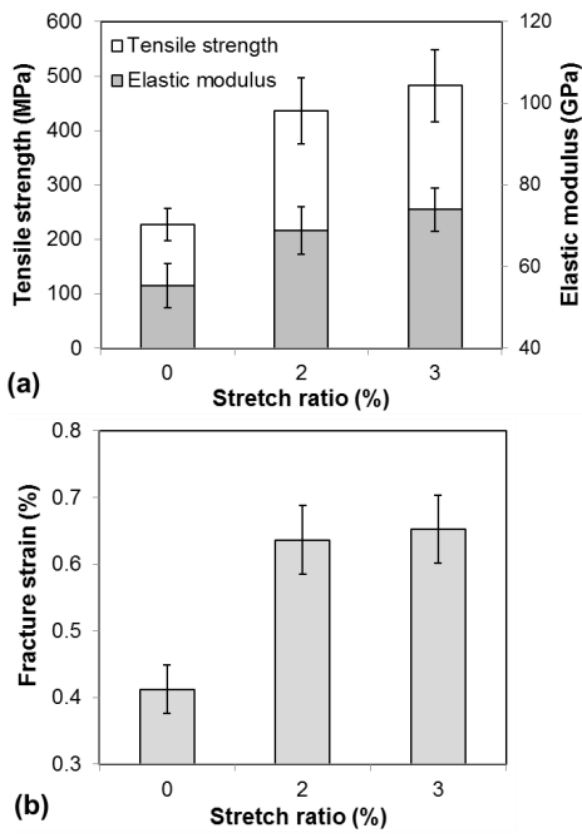

Figure 4. Mechanical properties of the pristine and stretched CNT/epoxy composites.

The measured mechanical properties of the epoxy resin and the composites show that the aligned CNTs greatly enhanced tensile strength and elastic modulus of epoxy resin. Compared to the epoxy resin, the pristine CNT/epoxy composite showed increased tensile strength by $252.6 \%$, enhanced elastic modulus by $207.6 \%$, and decreased fracture strain by $91.5 \%$. The improvement in the tensile strength and elastic modulus of the composites is explainable by the fact that the aligned CNTs in the composites carry the load along the length of CNTs and provide strength and stiffness in the loading direction [5-7]. As seen in Figure 2, most CNTs in the sheets are aligned in the drawing direction. In addition, the CNT alignment in the composites was maintained during resin impregnation using hot-melt prepreg processing (Figure 5). As observed in Figure 5a, the wavy 
and poor-packed CNTs are apparent in the pristine composites. After stretch-drawing, the wavy CNTs were straightened and the dense packing of CNTs was enhanced (Figures 5b$5 \mathrm{c})$. The reduction in the fracture strain of the composites is mainly attributable to the addition of high CNT contents, resulting in the decrease in the amount of epoxy matrix available for the elongation, as presented in erlier reports [5-7].

Furthermore, the stretch-drawing of the CNT sheets improved the mechanical properties of the aligned CNT/epoxy composites considerably (see Figure 4). The mechanical properties of the composites increased concomitantly with the increase of the stretch ratio up to $3 \%$. Compared with the pristine composite, the $2 \%$ and $3 \%$ stretched CNT/epoxy composites respectively showed an increase in tensile strength by $92.5 \%$ and $112.7 \%$, an improvement in elastic modulus by $24.3 \%$ and $33.6 \%$, and an enhancement in fracture strain by $54.4 \%$ and $58.4 \%$. The increase in the mechanical properties of the composites is attributed to the straightening of the wavy CNTs (Figure 2 and Figure 5) and a slight increase of the CNT volume fraction (Table 1). The aligned CNTs are self-assembled and are straightened along the CNT direction during the stretching. Consequently, the packing of CNTs in the stretched sheets (Figures 2b-2c) became more compact than that in the pristine sheets (Figure 2a). The straightening of the wavy CNTs caused by stretch-drawing was proved by the better alignment of CNTs in the sheets through the Gband intensity enhancement, as presented above.

FE-SEM images showing fracture surfaces of the composites are presented in Figure 6. As Figure 6 shows, the CNT bundles caused by the stretch-drawing are visible on the composite fracture surfaces. The existence of the CNT bundles is evidenced by the surface morphologies of the CNT sheets (see Figures $2 b-2 c)$.
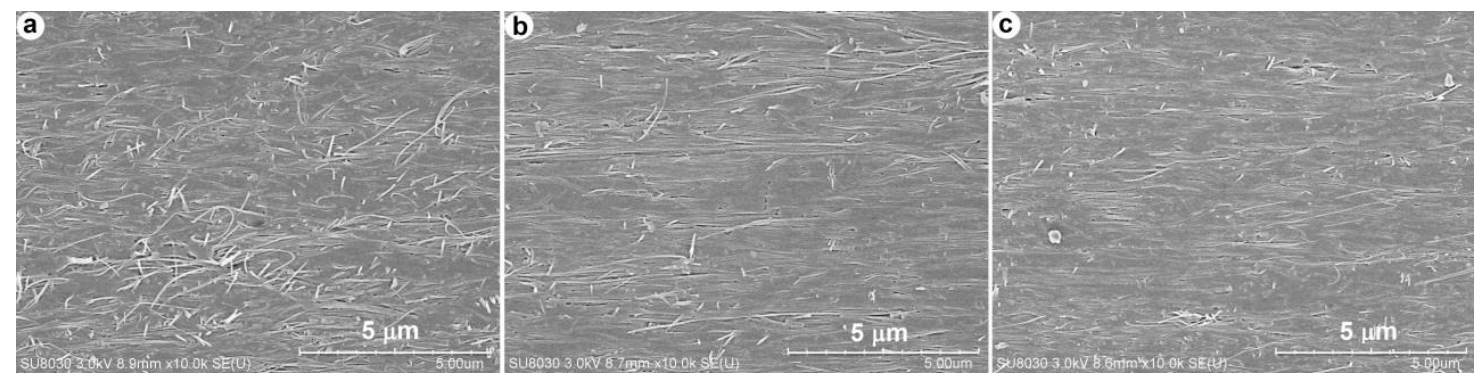

Figure 5. FE-SEM micrographs showing CNT distribution of (a) pristine, (b) $2 \%$ and (c) $3 \%$ stretched composites.
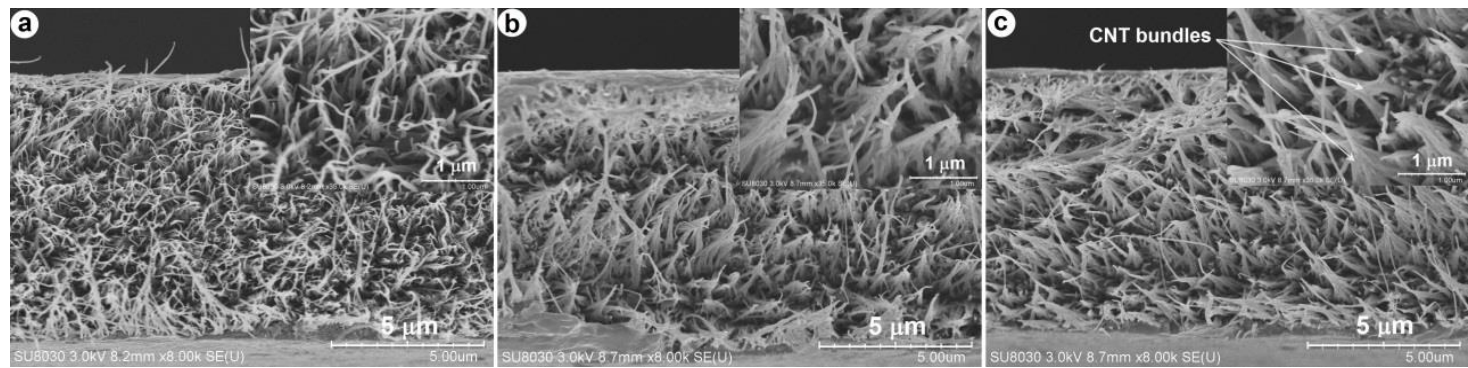

Figure 6. FE-SEM micrographs showing fracture surfaces of (a) pristine, (b) $2 \%$ and (c) $3 \%$ stretched composites.

\section{Trang 40}


As presented in our previous studies [6,7], stretching of the flat CNT sheets was effective for improving the mechanical properties of aligned CNT/epoxy composites. With the stretch ratio of $3 \%$, the 100-ply aligned CNT/epoxy composite showed the high tensile strength of 448.6 MPa and high elastic modulus of 67.4 GPa [6]. With the same CNT diameter and stretch ratio of $3 \%$, mean tensile strength (482.5 $\mathrm{MPa}$ ) and elastic modulus (73.9 GPa) of the stretched CNT/epoxy composite in this study respectively are higher than those of the one presented in the report [6]. Therefore, the stretch-drawing of the CNT sheets with round tube shaped in this study is more effective than the stretching of the flat CNT sheets described in our earlier reports.

\subsection{Evaluating the increase of CNT alignment in the composites caused by stretch-drawing}

The straightening of the wavy CNTs after stretch-drawing resulted in higher alignment of CNTs in the composites (Figure 5). The higher degree of the CNT alignment in the composites was examined using polarized Raman spectroscopy [7]. Typical polarized Raman spectra of the composite samples in the range of 1000-2000 $\mathrm{cm}^{-1}$ are presented in Figure 7. Raman spectroscopic measurements were conducted with incident light normal to the specimens, which was polarized parallel and perpendicular to the CNT alignment (see Figure 7 inset). Compared with the pristine samples, the stretched ones showed a lower D and G band peaks at $90^{\circ}$. The $\mathrm{G}$ band peaks decreased greatly for the stretched composites at the angle of $90^{\circ}$, thereby increasing the CNT alignment in the stretched composites.

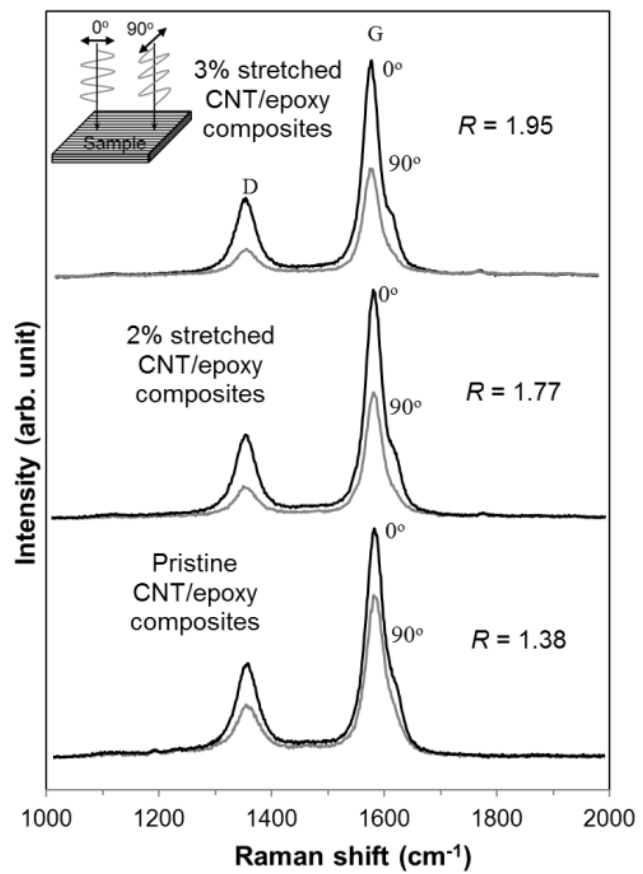

Figure 7. Polarized Raman spectra of pristine and stretched CNT/epoxy composites at $0^{\circ}$ and $90^{\circ}\left(0^{\circ}\right.$ and $90^{\circ}$ directions correspond to configurations where the polarization direction of the laser light are, respectively, parallel and perpendicular to the direction of CNTs).

Moreover, the higher degree of the CNT alignment in the composites engenders the higher G-band intensity ratio $R$. The G-band intensity ratio $R$ for the two polarizations of the pristine, $2 \%$, and $3 \%$ stretched composites respectively are $1.38,1.77$, and 1.95. These values show that the G-band intensity ratio of the composite samples is increased after applying the stretch-drawing of the CNT sheets. The enhancement of the G-band intensity ratio is ascribed to the better alignment of CNTs in the composites caused by stretch-drawing of the CNT sheets. The G-band intensity ratio of the $3 \%$ stretched composite exhibited the highest value among all the composites, thereby achieving the best mechanical properties of the aligned CNT/epoxy composites in this study. 


\section{CONCLUSIONS}

The simple stretch-drawing has produced highly aligned CNT sheets with dense packing of CNTs. Raman spectra measurements showed a higher alignment of CNTs in the sheets and their composites after the stretch-drawing. The stretch-drawing of the CNT sheets improved the mechanical properties of the composites considerably. The improved properties of the composites proceeded from straightening of the wavy CNTs and increasing the dense packing of CNTs caused by the stretch-drawing. The mechanical properties of the composites increased gradually with the increase of the stretch ratio up to $3 \%$. With a $3 \%$ stretch ratio, the aligned CNT/epoxy composites achieved their best mechanical properties in this study. In short, the simple stretch-drawing is effective to produce highly aligned and dense-packed CNT sheets for the development of high-performance CNT composites. Particularly, the stretchdrawing of the CNT sheets in this study is more effective than the stretching of flat CNT sheets presented in our previous studies. 


\section{Cải thiện tính chất cơ học của vật liệu compozit nền epoxy gia cường ống cácbon nano định hướng bằng phương pháp nong- kéo đơn giản}

- Trần Hũu Nam - E-mail: namth@pvu.edu.vn

- Vũ Minh Hùng

- Phạm Hồng Quang

Trường Đại học Dầu khí Việt Nam

\section{TÓM TẮT}

Các tấm mỏng ống nano cácbon (CNT) đa thành định hướng ngang đã được chế tạo tù̀ các mảng CNT định huớng dọc bằng phuoong pháp kéo và quấn. Vật liệu compozit nền epoxy gia cuờng các CNT định huớng đã được phát triển trên co sở tấm mỏng với 100 lớp CNT định huoóng bằng phuơng pháp ép nóng chảy bán thành phẩm của chúng. Tuy nhiên, độ cong và sư sắp xếp không chặt của các CNT trong tấm mỏng đã làm giảm khả năng truyền lực của chúng trong compozit. Do đó, một phuoong pháp nongkéo đơn giản đã được sủ dụng để biến đổi cấu trúc của các tấm mỏng CNT định huớng nhằm cải thiện các tính chất của compozit. Kết quả đo trình bày trong bài báo chỉ ra rằng phuơng pháp nong-kéo đơn giản đã làm tăng đáng kể co tính compozit bắt nguồn tù sụ duỗi thẳng của các CNT cong và tù sư tăng độ sắp xếp chặt của các CNT trong compozit. Trong nghiên cứu này compozit có tính chất co học cao nhất tuơng úng với tỷ lệ nong-kéo là 3\%. So với compozit không nong-kéo thì compozit nong-kéo 3\% có độ bền kéo, và môđun đàn hồi cao hơn tuơng úng là $113 \%$ và $34 \%$. Nhìn chung, các kết quả nghiên cúu cho thấy hiệu quả của phuong pháp nongkéo đon giản là tạo ra được các tấm mỏng CNT định hướng cao có thể sử dụng để phát triển các compozit với đặc tính cao cấp. So với phuoong pháp kéo tấm mỏng đã trình bày trong một số nghiên cúu truớc, phuoong pháp nong-kéo trình bày trong nghiên cứu này hiệu quả hơn trong việc cải thiện co tính của CNT compozit.

của compozit. Sư cải thiện các tính chất của

Tù̀ khóa: Ông nano cácbon, bán thành phẩm, compozit, nong-kéo, tính chất co học.

\section{REFERENCES}

[1]. Thostenson E.T., Ren Z., Chou T.W. Advances in the science and technology of review. Composites Science and Technology carbon nanotubes and their composites: a 61(13), 1899-1912 (2001). 
[2]. Coleman J.N., Khan U., Blau W.J., Gun'ko Y.K. Small but strong: a review of the mechanical properties of carbon nanotubepolymer composites. Carbon 44(9), 16241652 (2006).

[3]. Inoue Y., Kakihata K., Hirono Y., Horie T., Ishida A., Mimura H. One-step grown aligned bulk carbon nanotubes by chloride mediated chemical vapor deposition. Applied Physics Letters 92(21), 213113 (2008).

[4]. Inoue Y., Suzuki Y., Minami Y., Muramatsu J., Shimamura Y, Suzuki K, et al. Anisotropic carbon nanotube papers fabricated from multiwalled carbon nanotube webs. Carbon 49(7), 2437-2443 (2011)

[5]. Ogasawara T., Moon S.Y., Inoue Y., Shimamura Y. Mechanical properties of aligned multi-walled carbon nanotube/epoxy composites processed using a hot-melt prepreg method. Composites Science and Technology 71(16), 1826-1833 (2011).

[6]. Nam T.H., Goto K., Oshima K., Premalal V., Shimamura Y., et al. Effects of stretching on mechanical properties of aligned multi-walled carbon nanotube/epoxy composites. Composites Part A 64, 194-202 (2014).

[7]. Nam T.H., Hung V.M., Thang V.Q. A study on improving properties of aligned multiwalled carbon nanotube/epoxy composites. The University of Danang - J. Sci. Technol. 97(1), 38-42 (2015).

[8]. Liu W., Zhang X., Xu G., Bradford P.D., Wang X., Zhao H., et al. Producing superior composites by winding carbon nanotubes onto a mandrel under a poly(vinyl alcohol) spray. Carbon 49(14), 4786-4791 (2011).

[9]. Ji J., Sui G., Yu Y., Liu Y., Lin Y., Du Z., et al. Significant improvement of mechanical properties observed in highly aligned carbon-nanotube-reinforced nanofibers. $J$. Phys. Chem. C 113(12), 4779-4785 (2009).

\section{Trang 44}

